of the specific gravity of the carcass. Within the range of slaughter weights used in France (90 to I Io $\mathrm{kg}$ live weight) and for this sample of $\mathrm{I} 45$ dissected carcasses, it was rather the degree of muscle development than that of fatness which seemed to be related to carcass weight $(\mathrm{r}=+0.55$ and +0.09 , respectively). This result is important for correction grades of fatness according to classes of carcass weight (HAMELIN and Desmoulin, 1975). Further investigations are undertaken at the present time to compare the values of the different fatness indexes.

\title{
Performances and careass traits in restricted pigs fed with maize and slaughtered between 90 and 115 kg̣ live weight
}

\author{
J. CASTAING, M. LEUILLF'T \\ Association générale des Producteurs de Waïs, \\ 1. place S. de Lestapis, \\ 64000 Pau \\ Institut Technique des Céréales et des Fonrrages, \\ 8, avenue du Président Wilson, \\ 75116 Paris
}

This study was made in order to determine the evolution of performances in pigs restricted from $60 \mathrm{~kg}$ live weight $(2.3 \mathrm{~kg} /$ day $/$ animal) for castrated males and from $80 \mathrm{~kg}(2.8 \mathrm{~kg} / \mathrm{day} / \mathrm{anima})$ for females. The pigs were slaughtered between 90 and $\mathrm{II}_{5} \mathrm{~kg}$ live weight.

The main result concerns the almost linear increase of feed conversion in connection with a reduction of growth rate. These effects tended to increase the production costs for heavy pigs.

On the other hand, the carcass weight produced per pig increased as a consequence of the gain in live weight and, accessorily, in yield. Furthermore, it was noted that within the weight classes studied, the commercial grading of the carcasses exhibited constant values.

Thus, on account of the prevailing economic conditions during this trial (early 1975) the locst margin per pig produced was obtained with the heaviest carcasses.

These findings confirm the trends observed in a previous trial (BOUARD and LELILLET, 1975) and will be confirmed under conditions of restricted group feeding with a greater number of animals. 